\title{
Rheological behaviour of whole wheat flour
}

\author{
$\underline{\text { Haros, }}$ M. $^{1}$, Ana Ferrer and Cristina M. Rosell \\ Institute of Agrochemistry and Food Technology (IATA-CSIC), P.O. Box 73, 46100 - \\ Burjassot, Valencia - Spain. \\ 1e-mail: mharos@iata.csic.es
}

\begin{abstract}
During transformation of flour into bread, phytate content decreases as consequence of the activity of native phytase, but usually not to such extent to greatly improve mineral bioavailability in whole wheat products being the particle size distribution of bran one of the most important variable to take into consideration because the major phytate concentration is located in the bran.

The goal of this investigation was to study the effect of fungal phytase, $\alpha$-amylase addition, particle size distribution, and their interactions, on the rheological behaviour of the wholewheat flour. Mixing and pasting parameters were recorded in the Mixolab equipment. The parameters studied -hydration, development time, mixing stability, protein weakening (C2 and alpha), starch gelatinisation (C3 and beta), amylasic activity (C4 and gamma) and starch gelling (C5)- were analysed using a multivariate design with three levels of $\alpha$-amylase dose $(0,10$ and $20 \mu \mathrm{mL} / 100 \mathrm{~g}$ of flour), three levels of fungal phytase dose (0, 100 and 200 $\mu \mathrm{mL} / 100 \mathrm{~g}$ of flour) and two levels of particle size distribution of bran ( $\geq 500 \mu \mathrm{m}$ and $<500 \mu \mathrm{m})$. Response surface plots were used to show the single effects and second-order interactions of the different factors.

The particle size distribution of bran affected mainly the hydration and the parameters related to starch gelatinisation, whereas the $\alpha$-amylase the $C 4$, gamma and $C 5$. The phytase affected the parameters related to water absorption and amylasic activity, where the secondorder interactions had bigger order of importance.
\end{abstract}

Key words: whole wheat flour, rheological behaviour, Mixolab, $\alpha$-amylase, fungal phytase

\section{INTRODUCTION}

There is continuing interest in providing dietary options that deliver increased fibre and reduced glycemic or cholesterol index. However, the selection of the base flour has a strong effect on the ability to formulate an acceptable bread product given nutritional benefits. It has been already established that rheological tests on dough can predict their behaviour in a bakery, although only if the rates and the extent of the deformation in these test are in the same range as those during dough processing (Dobraszczyk and Roberts, 1994; Van Vliet et al., 1992). In addition, pasting properties highly correlate with bread staling kinetics parameters, specially in the case of peak viscosity, pasting temperature and setback, whose are useful predictors of bread firming behaviour during storage (Collar, 2003).

Enzymes as technological aids are usually added to flour, during mixing step of the breadmaking. The enzymes most frequently used in bread making are the $\alpha$-amylases from different origins (Rosell et al., 2001). The effects associated with the use of $\alpha$-amylases are an increase in the bread volume, an improvement of crumb grain, crust and crumb colour, and a contribution to the flavour development (Rosell et al., 2001). Calcium ion is required for the stability of $\alpha$-amylases, is a co-factor, whereas the phytic acid has an inhibitory effect in the amylase activity by sequestrating of this cation (Haros et al., 2001a). Phytic acid, myo-inositol 
hexaphosphate or phytate, is widely distributed in plant seeds and grains. It is primarily present as a salt of mono- and divalent cations $\left(\mathrm{K}^{+}, \mathrm{Ca}^{2+}\right.$ and $\left.\mathrm{Mg}^{2+}\right)$, but phytates have adverse effects on the bioavailability of multivalent cations, due to the formation of insoluble complexes (Zemel and Shelef, 1982; Muñoz, 1985). During transformation of flour into bread, phytate content decreases as consequence of the activity of native phytase, but usually not to such extent to greatly improve mineral bioavailability in whole wheat products. Reduction of phytate content during breadmaking depends of phytase activity, degree of flour extraction, proofing time and temperature, $\mathrm{pH}$ of dough, the yeast, and enzymes added and the presence of calcium salts (Türk and Sandberg, 1992). The fungal phytase can improve nutritional and breadmaking performance of whole wheat bread (Haros et al., 2001b).

The main objective of this investigation was to study the effect of fungal phytase, $\alpha$-amylase addition, bran particle size distribution, and their interactions, on the rheological behaviour of the whole-wheat flour by using the Mixolab equipment.

\section{MATERIALS AND METHODS}

\section{MATERIALS}

Commercial whole wheat flour was purchased from local market. The characteristics of the commercial whole wheat flour used were: moisture $14.52 \%$, protein $(\mathrm{N} \times 5.7) 11.61 \%$ dry matter (d.m.), lipid content $1.7 \%$ d.m., and ash $1.34 \%$ d.m. Particle size distribution of the whole wheat flour before grinding the bran was determined by using a set of standard sieves (CISA, Barcelona, Spain) (Table 1). In order to diminish the bran particle size and to avoid the damage of the starch granules the following procedure was carried out. The whole flour was sieved and the fractions bigger than $500 \mu \mathrm{m}$ were ground in a laboratory mill (Nanlysenmühle A10, Janke \& Kunkel, Germany) for reducing its particle size to less than $500 \mu \mathrm{m}$. Then, the resulting fraction was blended with the rest of the flour with the purpose of reconstituting it completely.

Table 1. Particle size distribution of whole wheat flour

\begin{tabular}{cc}
\hline$\mu \mathrm{m}$ & $\%, \mathrm{w} / \mathrm{w}$ \\
\hline$>1000$ & 5.29 \\
$840-1000$ & 0.82 \\
$707-840$ & 1.18 \\
$595-707$ & 5.48 \\
$500-595$ & 37.43 \\
$<500$ & 46.45 \\
\hline
\end{tabular}

The enzymes tested were commercial phytase (3.13.8) from Aspergillus niger (Ronozyme Phytase Novo) and fungal commercial $\alpha$-amylase from Aspergillus oryzae (Fungamyl BG), which were gifted by Novo Nordisk (Bioindustrial, Spain).

\section{METHODS}

Mixing and pasting properties. Mixing and pasting behaviour of the wheat flour dough was studied using the Mixolab (Chopin, Tripette et Renaud, Paris, France), which allows mixing the dough under controlled temperature and also a temperature sweep until $90^{\circ} \mathrm{C}$ followed by a cooling step. It measures in real time the torque (expressed in $\mathrm{Nm}$ ) produced by passage of the dough between the two kneading arms, thus allowing the study of the physico-chemical behaviour of the dough. 
For the assays, 50 grams of whole wheat flour at two different bran size distributions were placed into the Mixolab bowl and mixed with different enzyme dose combinations following a design for sampling (see Factorial design and statistical analysis). The procedure followed for the analysis of the mixing and pasting behaviour is shown in Table 2.

Table 2. Instrumental settings defined in the Mixolab for running the samples

\begin{tabular}{lc}
\hline Settings & Values \\
\hline Mixing speed & $75 \mathrm{rpm}$ \\
Tank temperature & $30^{\circ} \mathrm{C}$ \\
Temperature $1^{\text {st }}$ plateau & $30^{\circ} \mathrm{C}$ \\
Duration $1^{\text {st }}$ plateau & Until the consistency reaches the value $0.90 \times 1.1 \mathrm{Nm}$ \\
Heating rate & $4^{\circ} \mathrm{C} / \mathrm{min}$ \\
Temperature $2^{\text {nd }}$ plateau & $90^{\circ} \mathrm{C}$ \\
Duration $2^{\text {nd }}$ plateau & $7 \mathrm{~min}$ \\
Cooling rate & $4^{\circ} \mathrm{C} / \mathrm{min}$ \\
Temperature $3^{\text {rd }}$ plateau & $50^{\circ} \mathrm{C}$ \\
Duration $3^{\text {rd }}$ plateau & $5 \mathrm{~min}$ \\
Total analysis time & $37 \mathrm{~min}+$ Duration $1^{\text {st }}$ plateau \\
\hline
\end{tabular}

The Mixolab allows to the characterisation of the physico-chemical behaviour of dough when submitted to a dual mixing and temperature constraints. Therefore, it was possible to record the mechanical changes due to mixing and heating simulating the mechanical work as well as the heat conditions that might be expected during the baking process (Rosell et al., 2006a)

The Figure 1 shows a typical Mixolab curve, in which five different stages can be distinguished.

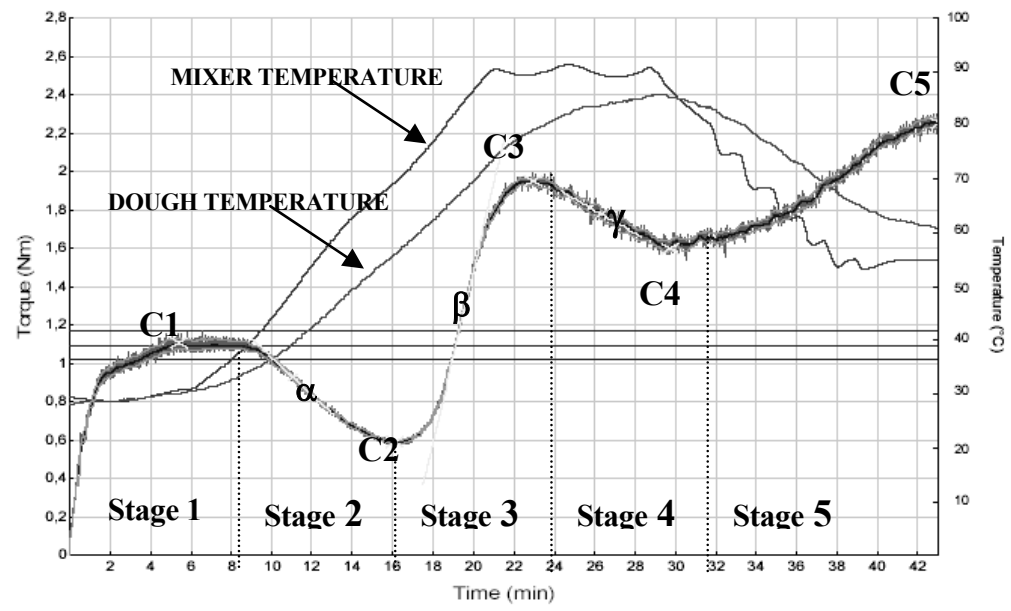

Figure 1. Rheological behaviour of wheat flour in the Mixolab.

The first one includes the initial mixing wherein the hydration of the flour compounds occurs together with the stretching and alignment of the proteins, leading to the formation of the viscoelastic structure. During this stage an increase in the torque was observed until a maximum was reached and resisted the deformation. During the second stage a decrease in the torque was observed, which is attributed to the weakening of the protein network for mechanical shear stress and protein destabilization until a minimum value (Rosell et al., 2006a). The temperature increases and the third stage starts with the gelatinisation of starch, the granules absorb the water available in the medium and they swell, so the viscosity increases. The amylase activity 
and the physical breakdown of the granules are associated with a reduction in the viscosity (fourth stage). A decrease of the temperature resulted in an increase of the torque, which is referred to setback and corresponds to the gelation process. This last stage is related to the retrogradation (Rosell et al., 2006a)

Parameters obtained from the recorded curve were: water absorption (\%) or percentage of water required for the dough to produce a torque of $1.1 \mathrm{Nm}$, dough development time (min) or time to reach the maximum torque at $30^{\circ} \mathrm{C}$, mixing stability ( $\mathrm{min}$ ) or elapsed time at which the torque produced is kept at $1.1 \mathrm{Nm}$, protein weakening (C2, Nm and alpha slope, $\mathrm{Nm} / \mathrm{min}$ ), starch gelatinisation $(\mathrm{C} 3, \mathrm{Nm}$ and beta slope, $\mathrm{Nm} / \mathrm{min})$, amylasic activity $(\mathrm{C} 4, \mathrm{Nm}$ and gamma, $\mathrm{Nm} / \mathrm{min})$ and starch gelling $(\mathrm{C} 5, \mathrm{Nm})$.

Factorial design and statistical analysis. In order to study the effect of particle size distribution, fungal phytase and $\alpha$-amylase on rheological behaviour of whole wheat flour a factorial design was used. The experiment design is an efficient tool that allows detecting interactions between a big number of concurring factors and which makes use the analysis of variance as statistical support (Montgomery, 1991).

The studied independent factors were: bran particle size in two levels $(\geq 500 \mu \mathrm{m}$ and $<500 \mu \mathrm{m})$; fungal phytase dose in three levels $(0,100$ and $200 \mu \mathrm{L} / 100 \mathrm{~g}$ of flour) and fungal $\alpha-$ amylase dose in three levels $(0,10$ and $20 \mu \mathrm{L} / 100 \mathrm{~g}$ of flour). The model resulted in 18 different combinations of experiments and the coded values per each level of each factor are presented in Table 3.

Table 3. Factorial design for sampling

\begin{tabular}{crrc}
\hline Run & $\boldsymbol{x}_{\boldsymbol{1}}$ & $\boldsymbol{x}_{2}$ & $\boldsymbol{x}_{3}$ \\
\hline 1 & -1.0 & -1.0 & -1.0 \\
2 & 1.0 & -1.0 & -1.0 \\
3 & -1.0 & 0.0 & -1.0 \\
4 & 1.0 & 0.0 & -1.0 \\
5 & -1.0 & 1.0 & -1.0 \\
6 & 1.0 & 1.0 & -1.0 \\
7 & -1.0 & -1.0 & 0.0 \\
8 & 1.0 & -1.0 & 0.0 \\
9 & -1.0 & 0.0 & 0.0 \\
10 & 1.0 & 0.0 & 0.0 \\
11 & -1.0 & 1.0 & 0.0 \\
12 & 1.0 & 1.0 & 0.0 \\
13 & -1.0 & -1.0 & 1.0 \\
14 & 1.0 & -1.0 & 1.0 \\
15 & -1.0 & 0.0 & 1.0 \\
16 & 1.0 & 0.0 & 1.0 \\
17 & -1.0 & 1.0 & 1.0 \\
18 & 1.0 & 1.0 & 1.0 \\
\hline
\end{tabular}

$\mathrm{x}_{1}$ : design factor particle size of bran. Coded values: -1.0 and 1.0 corresponding to $\geq 500 \mu \mathrm{m}$ and $<500 \mu \mathrm{m}$, respectively

$\mathrm{x}_{2}$ : design factor phytase dose. Coded values: $-1.0,0.0$ and 1.0 corresponding to 0,100 and $200 \mu \mathrm{L} / 100 \mathrm{~g}$ of flour, respectively $\mathrm{x}_{3}$ : design factor fungal $\alpha$-amylase dose. Coded values: $-1.0,0.0$ and 1.0 corresponding to 0,10 and $20 \mu \mathrm{L} / 100 \mathrm{~g}$ of flour, respectively

The design makes it possible to approximate the measured data $\left(y_{o b s}\right)$ with a response surface model expressed in coded values: 


$$
\begin{aligned}
& y_{o b s}=b_{0}+b_{1} x_{1}+b_{2} x_{2}+b_{3} x_{3}+b_{12} x_{1} x_{2}+b_{13} x_{1} x_{3}+b_{22} x_{2}^{2}+b_{23} x_{2} x_{3}+b_{33} x_{3}^{2}+b_{122} x_{1} x_{2}^{2}+ \\
& +b_{123} x_{1} x_{2} x_{3}+b_{133} x_{1} x_{3}^{2}+b_{223} x_{2}^{2} x_{3}+b_{233} x_{2} x_{3}^{2}+\varepsilon
\end{aligned}
$$

Where in the equation (1) $x_{1}$ is the design factor: bran particle size, $\mathrm{x}_{2}$ is the design factor: phytase dose and $x_{3}$ is the design factor: $\alpha$-amylase dose. The coefficients $b_{1}, b_{2}$ and $b_{3}$ are the main effects of $x_{1}, x_{2}$ and $x_{3}$, respectively. The square coefficients $\left(b_{i i}\right)$ will tell if any of variables has a maximum or minimum in the experimental domain, whereas the mixed coefficients represent the interactions between factors.

The difference between the experimental data $\left(y_{o b s}\right)$ and the model $\left(y_{\text {calc }}\right)$ gives the residual $(\varepsilon)$. $\mathrm{R}^{2}$ was calculated for each response, which is the fraction of variation of the response explained by the model.

Statistical analysis. Multivariate analysis (stepwise regressions and correlation matrix) and response surface plots of mixing and pasting parameters of rheological behaviour of whole wheat flour in Mixolab were performed using Statgraphics V.7.1 program (Bitstream, Cambridge, $\mathrm{MN}$ ).

\section{RESULTS AND DISCUSSION}

In dough development and breadmaking processes, response curves have been successfully used for optimising ingredients and processing conditions, being a useful tool when a number of processing conditions must be taken into account for defining a recipe or a process (Rosell et al., 2006b). Analytical data obtained from the factorial design on dough mixing properties were fitted to multiple regression equations using different levels of independent factors (Table 3) in order to estimate response surfaces (equation 1) of depending mixing dough variables (Table 4).

Table 4. Coefficients of the design factors ${ }^{\mathrm{a}}$ of for the mixing characteristics of the whole wheat dough.

\begin{tabular}{cccc}
\hline Coefficients & \multicolumn{3}{c}{ Mixolab parameters } \\
\cline { 2 - 4 } & Water absorption, \% & Development time, min & Stability, min \\
\hline $\boldsymbol{b}_{\boldsymbol{o}}$ & 59.30 & 8.203 & 11.60 \\
$\boldsymbol{b}_{1}$ & $0.092^{* * *}$ & $-0.626^{*}$ & 0.085 \\
$\boldsymbol{b}_{2}$ & $-0.598^{* * *}$ & $0.743^{*}$ & 0.130 \\
$\boldsymbol{b}_{3}$ & 0.000 & 0.290 & 0.313 \\
$\boldsymbol{b}_{12}$ & 0.002 & 0.017 & 0.380 \\
$\boldsymbol{b}_{13}$ & -0.003 & 0.158 & -0.039 \\
$\boldsymbol{b}_{22}$ & $-0.391 * * *$ & -0.465 & 0.583 \\
$\boldsymbol{b}_{23}$ & -0.003 & -0.129 & 0.358 \\
$\boldsymbol{b}_{33}$ & -0.003 & -0.488 & $0.941^{*}$ \\
$\boldsymbol{b}_{122}$ & 0.010 & -0.172 & $1.18^{* *}$ \\
$\boldsymbol{b}_{123}$ & 0.004 & -0.130 & -0.105 \\
$\boldsymbol{b}_{133}$ & -0.003 & -0.229 & $-1.218^{* *}$ \\
$\boldsymbol{b}_{223}$ & 0.000 & 0.000 & 0.000 \\
$\boldsymbol{b}_{233}$ & -0.008 & -0.609 & -0.750 \\
$\mathrm{R}-\mathrm{SQ}$ & 0.999 & 0.865 & 0.900 \\
\hline
\end{tabular}

${ }^{\mathrm{a}}$ The independent variables were bran size distribution (1), fungal phytase dose (2) and $\alpha$-amylase dose (3) $*, * *, * * *$ Significant coefficients $(90,95$ and $99 \%$ confidence interval, respectively)

${ }^{\mathrm{b}} \mathrm{R}-\mathrm{SQ}$ : adjusted square coefficient of the fitting model 
The presence of fungal $\alpha$-amylase had not significantly effect in the water absorption, dough development time and dough stability, whereas the particle size of bran and phytase had significant effect in the water absorption and dough development time. Concerning water absorption, the lower particle size distribution of bran promoted the largest increase in water absorption having positive linear significant effect, whereas this factor showed a negative linear effect ( $90 \%$ confidence interval) in the dough development time (Table 4). On the other hand, the addition of fungal phytase had a significant effect in the water absorption $(99 \%$ confidence interval), wherein the samples with phytase this parameter diminished until $1.2 \%$ (Figure 2).
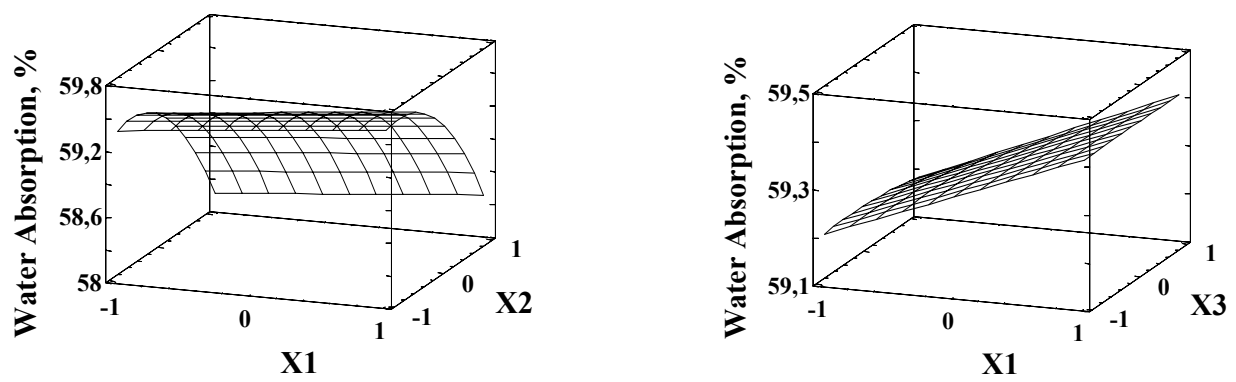

Figure 2. Response surface plots of the single and interactive effects of different factor in the water absorption used Mixolab. $\mathrm{x}_{1}, \mathrm{x}_{2}$ and $\mathrm{x}_{3}$ are the design factors: particle size of bran, phytase dose and fungal $\alpha$-amylase dose, respectively

This negative linear and quadratic significant effect could be due to the liberation of the cations and phosphates of the phytates, which increased the ionic strength of the mixture. These minerals interact with the protein, which are the main responsible of the absorption of water in the dough (Sliwinski et al., 2004) causing an increment in the dough development time (90\% confidence interval).

During the dough development a maximum was reached and then dough was able to resist the deformation for some time. The period of constant torque determines the dough stability. The amylase dose showed a negative quadratic effect $\left(b_{33}\right)$ and it interaction with the bran size $\left(b_{133}\right)$ in the whole dough stability, whereas the interaction between the bran particle size and phytase factor $\left(b_{122}\right)$ had a positive effect in it.

When the mixing is excessive the torque decrease, which is attributed to the weakening of the protein network. The combined effect of the mechanical shear stress and the temperature produced a decrease in the torque that could be related with the beginning of the protein destabilization and unfolding (Rosell et al., 2006a). The consistency C2, one of the reduction protein parameters obtained in Mixolab equipment, was affected negatively by the linear effect of the bran particle size (95\% confidence interval) and the negative quadratic effect of the phytase (95\% confidence interval), whereas the slope alpha was affected negatively by the linear effect of the amylase, its quadratic effect and its interaction with the phytase activity, as likewise with the interaction between the bran size and the phytase activity (Table 5). The minimum torque was detected in the range $54.0-57.5^{\circ} \mathrm{C}$, where further protein changes during heating might be masked by the modification of the physicochemical properties of the starch. 
Table 5. Coefficients of the design factors ${ }^{\mathrm{a}}$ of protein reduction parameters of the whole wheat dough in the Mixolab.

\section{Coefficients}

\section{Mixolab Parameters}

\begin{tabular}{ccc} 
& $\mathbf{C 2}, \mathbf{N m}$ & Alpha $\mathbf{x} \mathbf{1 0}, \mathbf{N m} / \mathbf{m i n}$ \\
\hline $\boldsymbol{b}_{\boldsymbol{o}}$ & 0.513 & -1.002 \\
$\boldsymbol{b}_{1}$ & $-0.017^{* *}$ & 0.014 \\
$\boldsymbol{b}_{2}$ & 0.008 & -0.028 \\
$\boldsymbol{b}_{3}$ & 0.001 & $-0.055^{* *}$ \\
$\boldsymbol{b}_{12}$ & -0.004 & 0.0008 \\
$\boldsymbol{b}_{13}$ & -0.005 & 0.0083 \\
$\boldsymbol{b}_{22}$ & $-0.014^{* *}$ & -0.026 \\
$\boldsymbol{b}_{23}$ & -0.001 & $-0.0300^{*}$ \\
$\boldsymbol{b}_{33}$ & -0.002 & $-0.0483^{*}$ \\
$\boldsymbol{b}_{122}$ & 0.004 & $-0.0758^{* *}$ \\
$\boldsymbol{b}_{123}$ & 0.007 & 0.0525 \\
$\boldsymbol{b}_{133}$ & 0.007 & 0.0417 \\
$\boldsymbol{b}_{223}$ & 0.000 & 0.0000 \\
$\boldsymbol{b}_{233}$ & -0.002 & $0.0700^{* *}$ \\
$\mathrm{R}-\mathrm{SQ}$ & 0.923 & 0.933 \\
\hline
\end{tabular}

${ }^{\mathrm{a}}$ The independent variables were bran size distribution (1), fungal phytase dose (2) and $\alpha$-amylase dose (3) $*, * *, * * *$ Significant coefficients $(90,95$ and $99 \%$ confidence interval, respectively)

${ }^{\mathrm{b}} \mathrm{R}-\mathrm{SQ}$ : adjusted square coefficient of the fitting model

As the temperature increases the role of the proteins goes to a secondary place, whereas the changes in the starch granules are the responsible of further torque variations. During this step the starch granules absorb water and swell, the viscoelasticity increases.

The gelatinisation stage only was affected by the bran particle size, which is the factor that showed a negative linear significant effect (95\% confidence level) in C3 and beta slope parameter (Table 6). Less effect had the interactions between the bran particle size and the $\alpha$ amylase or phytase dose ( $b_{133}$ and $b_{122}$, respectively). Response surface plots of gelatinisation parameters vs main factors are shown in Figure 3.
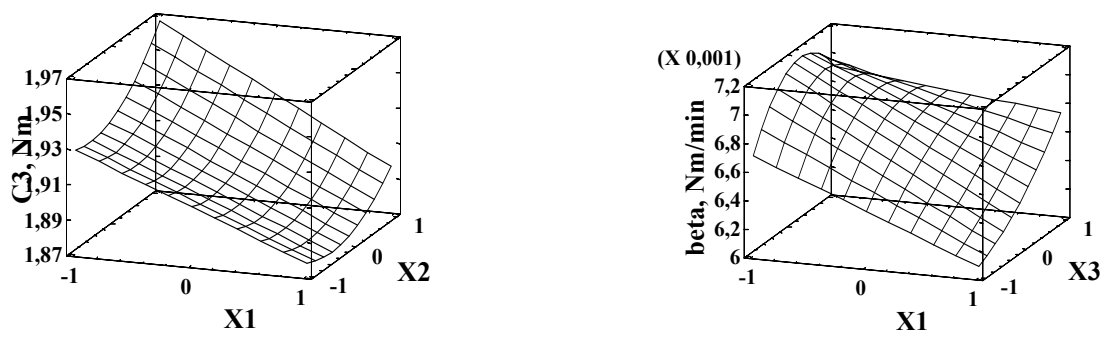

Figure 3. Response surface plots of the single and interactive effects of different factor in the starch gelatinisation of the whole wheat dough in the Mixolab. $\mathrm{x}_{1}, \mathrm{x}_{2}$ and $\mathrm{x}_{3}$ are the design factors: particle size of bran, phytase dose and fungal $\alpha$-amylase dose, respectively

The increment in the consistency continued until the mechanical shear stress and the temperature lead to the physical breakdown of the granules, which is reflected with a decrease 
of the viscoelasticity. A temperature decrease resulted in an increase of the torque due to the augmentation in the dough resistance for the starch gelling. The Mixolab stage which describes the setback and gelation process was strongly affected by the addition of $\alpha$-amylase enzyme to the dough, its effect on the dough rheological profile is showed in Figure 4. The values of $\mathrm{C} 4$ and gamma slope decreased when the fungal amylase dose increased. On the other hand, for both parameters the significant coefficient ( $99 \%$ confidence level) was the related to amylase dose factor with negative linear value (Table 6).

Table 6. Design factor coefficients ${ }^{\mathrm{a}}$ of pasting parameters of the whole wheat dough

Coefficients Mixolab Parameters

\begin{tabular}{cccccc}
\cline { 2 - 5 } & $\mathbf{C 3}$ & $\begin{array}{c}\text { Beta x 10 }^{3}, \\
\mathbf{N m} / \mathbf{m i n}\end{array}$ & $\begin{array}{c}\mathbf{C 4} \\
\mathbf{N m}\end{array}$ & $\begin{array}{c}\text { Gamma x 10 } \\
\mathbf{N m} / \mathbf{m i n}\end{array}$ & $\begin{array}{c}\mathbf{C 5} \\
\mathbf{N m}\end{array}$ \\
\hline $\boldsymbol{b}_{\boldsymbol{o}}$ & 1.905 & 6.733 & 1.498 & -1.063 & 1.899 \\
$\boldsymbol{b}_{1}$ & $-0.029^{* *}$ & $-0.414^{* *}$ & 0.041 & $0.161^{*}$ & 0.045 \\
$\boldsymbol{b}_{\mathbf{2}}$ & 0.015 & -0.178 & 0.002 & -0.018 & 0.009 \\
$\boldsymbol{b}_{3}$ & -0.008 & 0.220 & $-0.136^{* * *}$ & $-0.240^{* *}$ & $-0.294^{* * *}$ \\
$\boldsymbol{b}_{12}$ & -0.005 & 0.113 & -0.004 & 0.007 & 0.001 \\
$\boldsymbol{b}_{13}$ & -0.004 & 0.112 & -0.007 & -0.036 & -0.024 \\
$\boldsymbol{b}_{22}$ & 0.013 & -0.116 & 0.030 & 0.010 & $0.058^{*}$ \\
$\boldsymbol{b}_{23}$ & 0.003 & 0.205 & -0.001 & -0.009 & 0.003 \\
$\boldsymbol{b}_{33}$ & -0.003 & -0.123 & 0.025 & 0.118 & $0.128^{* * *}$ \\
$\boldsymbol{b}_{122}$ & -0.001 & $0.315^{*}$ & -0.007 & 0.007 & -0.010 \\
$\boldsymbol{b}_{123}$ & -0.001 & -0.135 & -0.004 & -0.020 & -0.003 \\
$\boldsymbol{b}_{133}$ & $0.020^{*}$ & 0.213 & 0.038 & 0.071 & 0.057 \\
$\boldsymbol{b}_{223}$ & 0.000 & 0.000 & 0.000 & 0.000 & 0.000 \\
$\boldsymbol{b}_{233}$ & 0.014 & 0.153 & 0.028 & 0.041 & 0.040 \\
$\mathrm{R}-\mathrm{SQ}^{\mathrm{b}}$ & 0.944 & 0.856 & 0.983 & 0.968 & 0.990 \\
\hline
\end{tabular}

${ }^{\mathrm{a}}$ The independent variables were bran size distribution (1), fungal phytase dose (2) and $\alpha$-amylase dose (3) $*, * *, * * *$ Significant coefficients (90,95 and 99\% confidence interval, respectively)

${ }^{\mathrm{b}} \mathrm{R}-\mathrm{SQ}$ : adjusted square coefficient of the fitting model

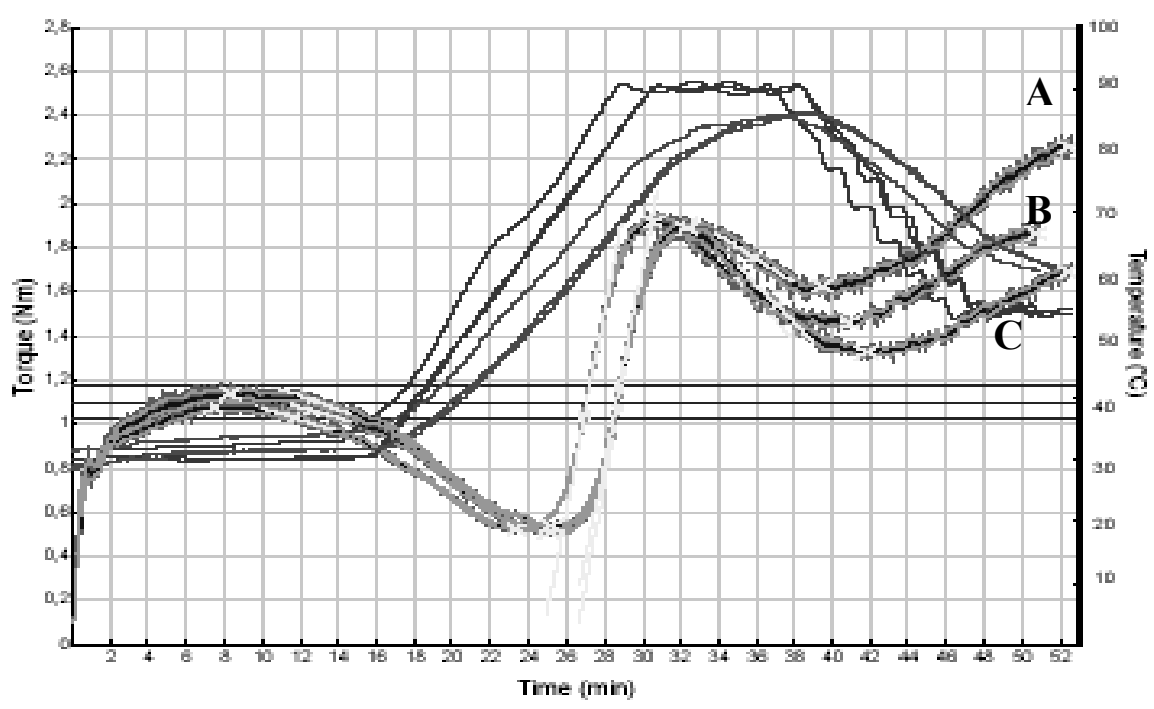

Figure 4. Effect of $\alpha$-amylase in the rheological profile of whole wheat flour in Mixolab.

A. 0.0 , B. 10.0 and C. $20.0 \mu \mathrm{L} / 100 \mathrm{~g}$ of flour 
With regard to the final viscosity (C5), it was affected negatively by the linear significant effect of the fungal amylase and the positive quadratic significant effect of the same factor ( $99 \%$ confidence interval), whereas the fungal phytase showed also a positive quadratic effect ( $90 \%$ confidence interval). These results indicate that the parameter C5 had a minimum value (Figure 5). Haros et al. (2001) reported that the phytase addition could liberate calcium from the phytate complexes, which free calcium ions become available as cofactor for the $\alpha$ amylase enzyme increasing its activity. The $\alpha$-amylase addition allowed a decrease in the setback, which indicates low rate of starch retrogradation (Rojas et al., 1999).
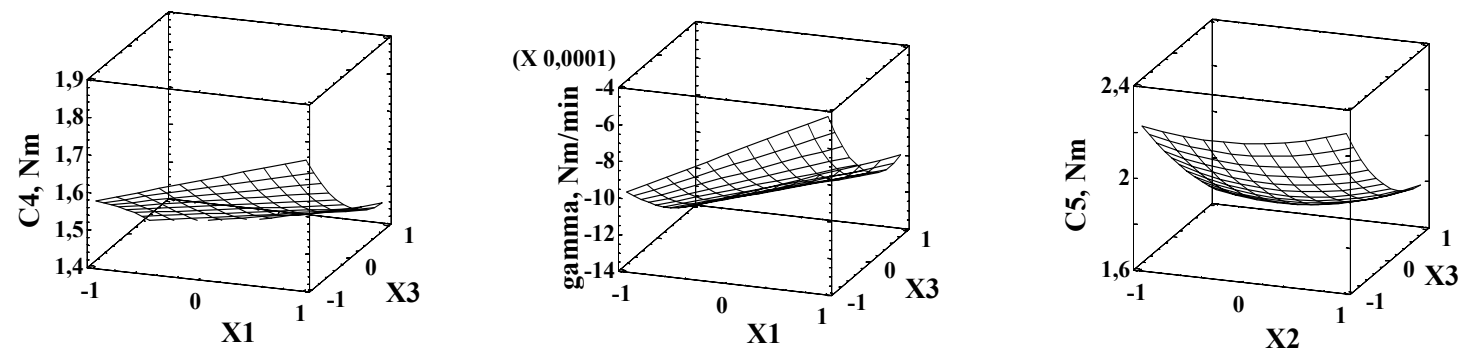

Figure 5. Response surface plots of the single and interactive effects of different factor in the pasting parameters of the whole wheat dough in the Mixolab. $\mathrm{x}_{1}, \mathrm{x}_{2}$ and $\mathrm{x}_{3}$ are the design factors: particle size of bran, phytase dose and fungal $\alpha$-amylase dose, respectively

\section{CONCLUSIONS}

Parameters that define dough mixing behaviour were significantly affected by the bran particle size distribution and the fungal phytase addition in the water absorption and dough development time, whereas the dough stability was not significantly affected by the studied factors, only their interactions seems to have effect.

The gelatinisation stage only was affected by the bran particle size distribution, whereas less effect had the interactions between the bran size and the $\alpha$-amylase or phytase addition. The setback and gelation process was strongly affected by the addition of $\alpha$-amylase enzyme to the dough. The Mixolab equipment is a good tool to study the rheological behaviour of whole wheat flour, sensitive to changes as flour granulometry and enzymes, like phytase and $\alpha$ amylase.

\section{ACKNOWLEDGEMENTS}

This work was financially supported by Ramón y Cajal Project, Ministry of Science and Technology, Spain. Authors would like to specially thank the Tripette et Renaud Chopin company for lending the Mixolab device.

\section{REFERENCES}

Bollaín, C. and Collar, C. 2005. Innovative evaluation of the rheological behaviour of bread dough controlling mixing energy and temperature. In: Proceedings Infradfood. Innovations in traditional foods. Volume II, pp. 37-40. Eds. Fito, P., Toldrá, F. Elsevier, London. 
Collar, C. 2003. Significance of viscosity profile of pasted and gelled formulated wheat doughs on bread staling. European Food Research and Technology, 216, 505-513.

Dobraszczyk, B. J. and Roberts, C. A. 1994. Strain hardening and dough gas cell vall failure in biaxial extension. Journal of Cereal Science, 20, 265-274.

Haros, M., Rosell, C.M. and Benedito, C. 2001a. Use of fungal phytase to improve breadmaking performance of whole wheat bread. Journal Agricultural of Food Chemistry, 49, 5450-5454.

Haros, M., Rosell, C.M. and Benedito, C. 2001b. Fungal phytase as a potencial breadmaking additive. European Food Research and Technology, 213, 317-322.

Montgomery, D.C. Design and analysis of experiments. 1991. John Wiley \& Sons Eds.

Muñoz, J.M. 1985. Overview of the effects of dietary fiber on the utilization of minerals and trace elements. In: Handbook of Dietary Fiber in Human Nutrition, Spiller, G.A. Ed.; CRC Press: Boca Raton, FL, pp 193-200.

Rojas, J.A., Rosell, C.M and Benedito, C. 1999. Pasting properties of different wheat flourhydrocolloid systems. Food Hydrocolloids, 13, 27-33.

Rosell, C.M., Haros, M., Escrivá, C. and Benedito de Barber, C. 2001. Experimental approach to optimize the use of a-amylases in breadmaking. Journal of Agricultural and Food Chemistry, 49(6), 2973-2977.

Rosell, C.M., Collar, C. and Haros, M. 2006a. Assessment of hydrocolloid on the thermomechanical properties of wheat using the mixolab. Food Hydrocolloids, in press.

Rosell, C.M., Santos, E., Collar, C. 2006b. Mixing properties of fibre-enriched wheat bread doughs: A response surface methodology study. European Food Research and Technology, 223, 333-340.

Sliwinski, E.L., van der Hoef, F. Kolster, P. And van Vliet, T. 2004. Large-deformation properties of wheat dough in uni- and biaxial extension. Part II. Gluten dough. Rheological Acta, 43, 321-332.

Türk, M. and Sandberg, A.-S. 1992. Phytate degradation during breadmaking: effect of phytase addition. Journal of Cereal Science, 15, 281-294.

Van Vliet, T., Janssen, A. M., Bloksma, A. H., and Walstra, P. 1992. Strain hardening of dough as a requirement for gas retention. Journal of Texture Studies, 23, 439-460.

Zemel, M.B. and Shelef, L.A. 1982. Phytic acid hydrolysis and zinc and iron in whole wheat bread as affected by calcium containing additives. Journal of Food Science, 47, 535-537. 